\title{
Multihour Stratospheric Flights with the Heliotrope Solar Hot-Air Balloon
}

\author{
Daniel C. Bowman, ${ }^{a}$ Paul E. Norman, ${ }^{b}$ Michael T. Pauken, ${ }^{c}$ Sarah A. Albert, ${ }^{a}$ \\ DARIELlE DEXHEIMER, ${ }^{a}$ XIAO YANG, ${ }^{\mathrm{d}}$ SIDDHARTH KRISHNAMOORTHY ${ }^{\mathrm{c}}$ ATTILA KOMJATHY, \\ AND JAMES A. CUTTS ${ }^{\mathrm{c}}$ \\ ${ }^{a}$ Sandia National Laboratories, Albuquerque, New Mexico \\ ${ }^{\mathrm{b}}$ University of Minnesota, Minneapolis, Minnesota \\ ${ }^{\mathrm{c}}$ NASA Jet Propulsion Laboratory, California Institute of Technology, Pasadena, California \\ ${ }^{\mathrm{d}}$ University of North Carolina at Chapel Hill, Chapel Hill, North Carolina
}

(Manuscript received 17 October 2019, in final form 16 April 2020)

\begin{abstract}
Standard meteorological balloons can deliver small scientific payloads to the stratosphere for a few tens of minutes, but achieving multihour level flight in this region is more difficult. We have developed a solarpowered hot-air balloon named the heliotrope that can maintain a nearly constant altitude in the upper troposphere-lower stratosphere as long as the sun is above the horizon. It can accommodate scientific payloads ranging from hundreds of grams to several kilograms. The balloon can achieve float altitudes exceeding $24 \mathrm{~km}$ and fly for days in the Arctic summer, although sunset provides a convenient flight termination mechanism at lower latitudes. Two people can build an envelope in about $3.5 \mathrm{~h}$, and the materials cost about $\$ 30$. The low cost and simplicity of the heliotrope enables a class of missions that is generally out of reach of institutions lacking specialized balloon expertise. Here, we discuss the design history, construction techniques, trajectory characteristics, and flight prediction of the heliotrope balloon. We conclude with a discussion of the physics of solar hot-air balloon flight.
\end{abstract}

\section{Introduction}

Ever smaller, lighter, and cheaper sensors are leading to new opportunities in atmospheric science. The primary challenge in free atmosphere investigations is therefore shifting to the flight systems-the means of delivering the sensors to the target region. This is particularly difficult for studies that require multihour level flight in the upper troposphere and lower stratosphere. Standard meteorological balloons continuously ascend and then burst, resulting in short residency times. Multihour level flights can be achieved by tethering a "tow" and "float" balloon together, then severing the connection at the desired altitude. However, this method may be complex, unreliable, and difficult to launch. Small zero-pressure or superpressure balloons can be fielded, but these tend to be much more expensive and require a reliable means of flight termination for successful recovery. Finally, the dramatic increase in helium prices (Kramer 2019) motivates the development of alternative lighterthan-air systems.

Corresponding author: Daniel C. Bowman, dbowma@sandia.gov
Solar-powered hot-air balloons can deliver gram- to kilogram-scale payloads for multihour float times in the lower stratosphere without requiring lift gas. They are inexpensive, simple to manufacture (even by the research teams themselves), and reliably land after sunset. Here, we describe the design, performance, and physics of the heliotrope, a solar-powered hot-air balloon that we developed and then fielded 26 times in the last 4 years. We provide detailed construction techniques, examine the performance of the flight system, and outline the physics that control the balloon's trajectory. We demonstrate that the heliotrope is an ideal vehicle for missions involving lightweight sensors that also require low per-launch costs. Finally, as the cost of helium continues to rise, solar-powered balloons could easily augment standard meteorological balloons for sounding the troposphere and lower stratosphere.

\section{Development history}

The first solar hot-air balloons were built and tested in the early 1970s (Besset 2016). Later, the Centre National d'Études Spatiales (CNES) developed the Montgolfière 
Infrarouge (MIR) balloon, which was able to utilize solar power during the day and infrared radiation from Earth's surface at night to stay aloft indefinitely. These balloons were used for investigations of the lower tropical stratosphere (Christensen et al. 2007) and the winter Arctic vortex (Pommereau et al. 2002). They were capable of staying aloft for over 60 days and reaching altitudes of $30 \mathrm{~km}$ (Malaterre 1993). A Jet Propulsion Laboratory group investigated the prospect of solar hot-air balloons on other planets (Jones and $\mathrm{Wu}$ 1999) and performed their own test flights on Earth (Jones and Heun 1997). They demonstrated that solar hot-air balloons can be deployed by simply dropping them from a height of several hundred meters and allowing them to ram inflate. They also developed an altitude-controlled solar hot-air balloon that used a remotely operated top vent to perform vertical maneuvers.

Reports of solar hot-air balloons reaching altitudes in excess of $15 \mathrm{~km}$ inspired us to begin developing our own. Our first design to achieve positive lift was an approximately $4 \mathrm{~m}$ spherical envelope that raised a $900 \mathrm{~g}$ bucket off the ground. Following this proof of concept, a $6 \mathrm{~m}$ envelope was constructed in May 2012 that carried a $1.8 \mathrm{~kg}$ payload consisting of messages in bottles. The balloon was tracked until it exceeded an elevation of approximately $3000 \mathrm{~m}$; bottle recoveries by beach goers over subsequent weeks demonstrated that the payload had landed in the ocean as anticipated. For the next 3 years we experimented with cylindrical, tetrahedral, and spherical balloons. Most were small and did not have tracking capabilities.

In 2015 we decided to attempt a full-day solar hot-air balloon flight. The balloon ascended to over $22 \mathrm{~km}$ over several hours, but the flight terminated just after reaching float. The cause of failure was determined to be the dark-colored tape used to attach the payload to the balloon envelope. The design flaw was rectified and two more flights were conducted in 2016, both of which remained aloft until sunset. A microbarometer on the second flight captured low-frequency sound waves, or "infrasound," from a ground explosion $330 \mathrm{~km}$ away (Young et al. 2018). We used solar hot-air balloons to deploy multiple infrasound microbarometers in the lower stratosphere as part of the Heliotrope experiment in 2017 (Bowman and Albert 2018). We then designated the quasi-spherical balloon envelope design used in this and previous missions as "heliotrope." A year later, we demonstrated that heliotropes could be towed aloft and released from a standard meteorological balloon, removing the need for low winds and clear skies at launch.

We have also experimented with long-duration flights during the Arctic summer, with launches taking place from Oliktok Point, Alaska. Two attempts in 2017 ended in failure because the balloons were launched too late in the season. However, one balloon launched in 2018 remained in flight for at least $72 \mathrm{~h}$ and perhaps longer (the tracker's battery eventually ran out). A solar-powered payload on a heliotrope launched during the Arctic summer could likely collect data from the lower stratosphere for weeks.

\section{Heliotrope construction}

The heliotrope balloon is a spherical envelope constructed from plastic sheeting and tape. Charcoal powder is used to darken the inner surface, allowing the balloon to absorb heat. The total cost of a $6 \mathrm{~m}$ balloon (capable of delivering a $700 \mathrm{~g}$ payload to approximately $23 \mathrm{~km}$ altitude) is about $\$ 30$ and takes two people $3.5 \mathrm{~h}$ to assemble.

We build the envelope using $0.31 \mathrm{mil}(7.87 \mu \mathrm{m})$, $400 \mathrm{ft} \times 12 \mathrm{ft}(120 \mathrm{~m} \times 3.6 \mathrm{~m})$ rolls of clear high-density plastic sheeting, usually listed as "light-duty painter's plastic" in hardware stores. This is the thinnest-and therefore the lightest-material commonly available. The number of gores is determined by the size of the balloon and the width of the sheet. This is why our balloons typically have a circumference that is a multiple of $12 \mathrm{ft}$. Our standard $6 \mathrm{~m}$ envelope, for example, has five gores that are $12 \mathrm{ft}$ wide at the equator and $30 \mathrm{ft}(\sim 9 \mathrm{~m})$ from pole to pole. The diameter of the resulting balloon is therefore slightly less than $6 \mathrm{~m}$.

The construction method for this size is described below; larger or smaller balloons can be built by adjusting these steps accordingly. Supplies consist of one $400 \mathrm{ft} \times$ $12 \mathrm{ft}$ roll of clear 0.31 mil high-density polyethylene plastic, about $200 \mathrm{ft}$ of clear shipping tape, permanent marker, binder clips, measuring tape, paracord, stiff plastic tubing (for a bottom vent if the balloon will be towed aloft), and carabiners. Black plastic sheeting is not as suitable for the envelope because it tends to be both thicker and weaker than light-duty painter's plastic. First, we cut five 30-ft strips from the painter's plastic roll and unfold them to make $30 \mathrm{ft} \times 12 \mathrm{ft}$ rectangles of plastic (Fig. 1a), fold them twice, and stack them on top of each other (Fig. 1b). It is critical that each sheet in the stack is oriented in the same manner, and that all the edges are aligned. This is best accomplished by using binder clips or heavy books on each corner and along midpoints to keep the plastic from shifting. Then, the gore pattern is drawn on the topmost sheet of the stack (Fig. 1c) and the plastic is cut (Fig. 1d). This generates five gores with the correct curve (one-quarter sine, since the envelope is spherical). Figure 2 shows a step-by-step schematic of this process. If multiple balloons are to be constructed, it can be more 

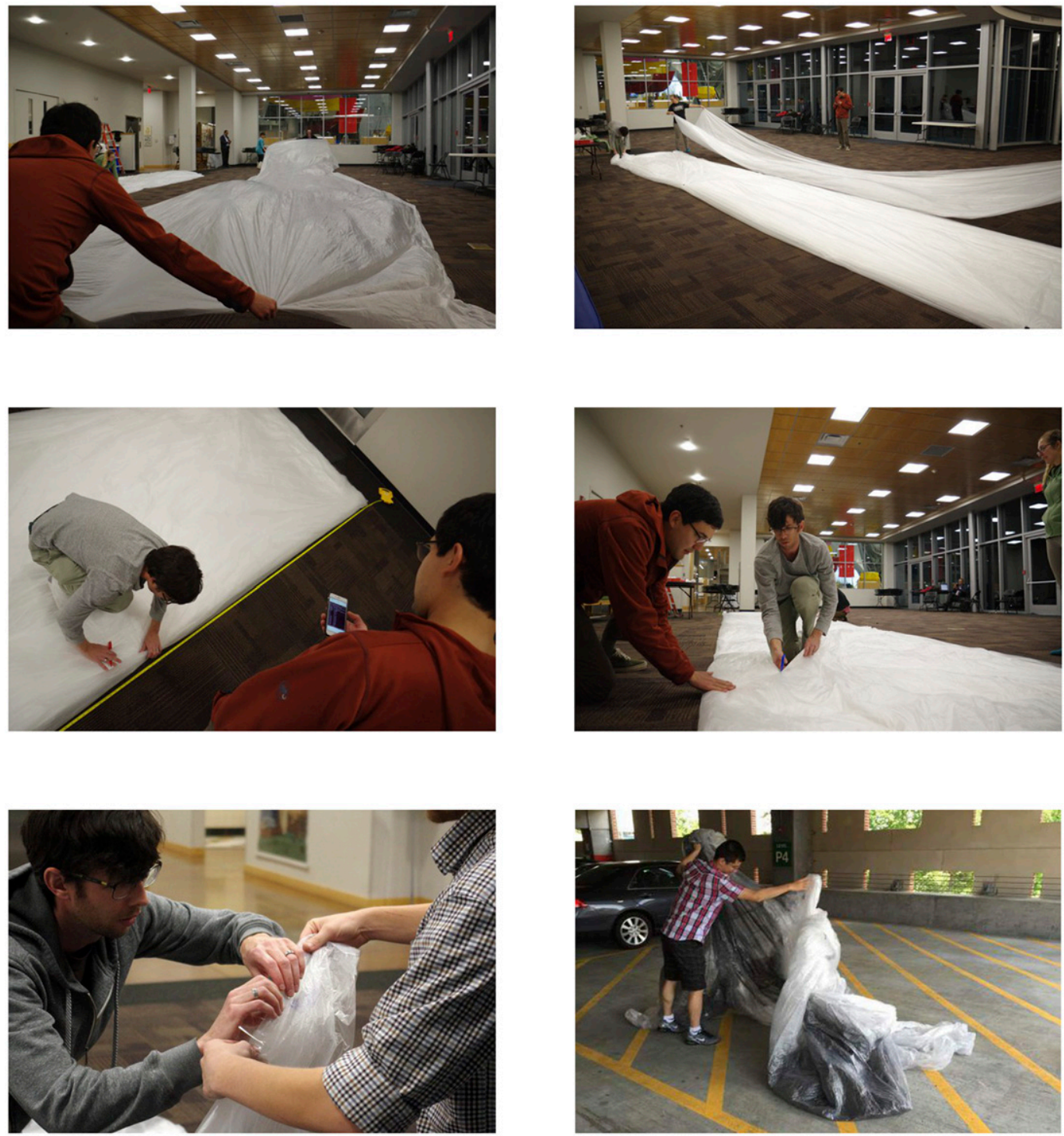

FIG. 1. Steps in building a solar hot-air balloon. (top left) Laying out plastic. (top right) Folding and stacking plastic sheets. (middle left) Measuring the gore curve. (middle right) Cutting the gore. (bottom left) Taping the gores together. (bottom right) Darkening the balloon envelope.

efficient to make a gore pattern from poster board or other light, stiff material and then overlay it on top of the plastic instead of remeasuring the curve each time.

The curve is defined by

$$
w=\frac{c}{2 n} \cos \left(2 \pi \frac{l}{c}\right)
$$

where $w$ is the width measured from the fold axis along the center of the gore, $c$ is the circumference of the balloon, $n$ is the number of gores desired, and $l$ ranges from 0 (the center of the gore; one corner of the twice-folded sheet) to $c / 4$. See Fig. 2 for a visualization of this curve.
Once the gores are cut, they are taped together (Fig. 1e). Clear shipping tape is best. Dark-colored tapes are not as adhesive and can become overheated during flight, causing failure. It is also possible to weld the gores together using a clothes iron, impulse sealer, or similar device, but the gore seams tend to be weaker. Each segment of tape should overlap the previous one to produce one continuous seal from pole to pole, because holes larger than a few centimeters across make it impossible to gain positive lift. The top of the balloon can be simply bunched together and taped, although this may lead to excessive stress. Instead, a "cap" of balloon material a few tens of centimeters across can be made 

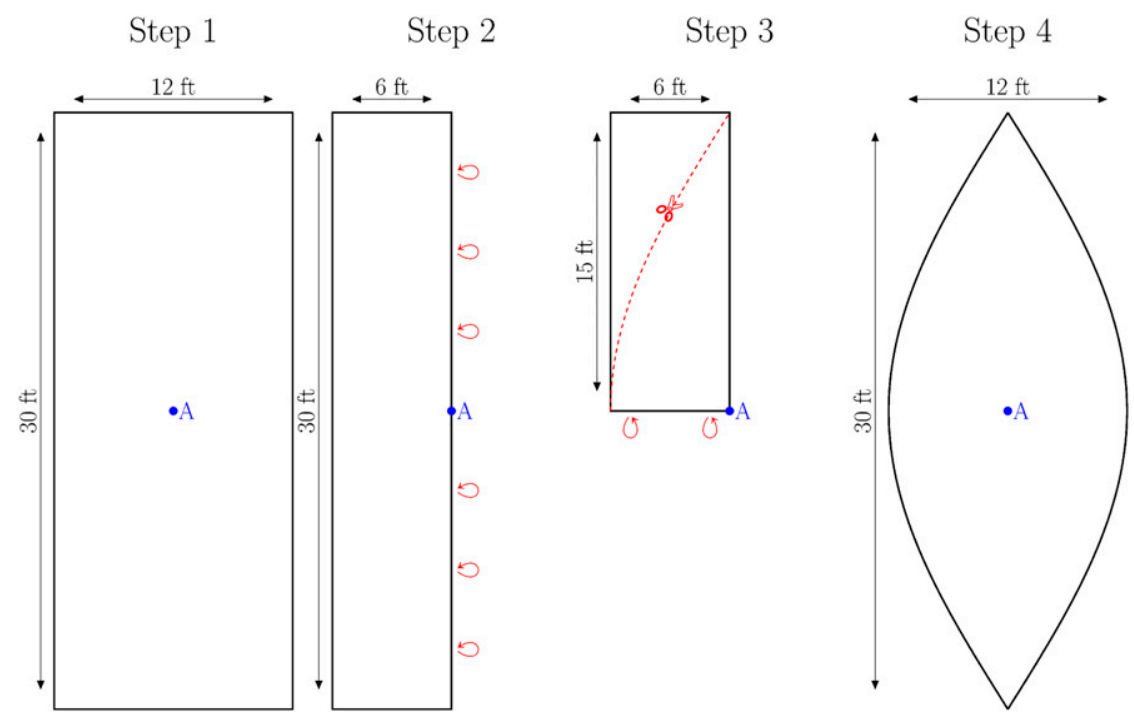

FIG. 2. Plastic folding and gore cutting sequence for a $60 \mathrm{ft}$ circumference (5.8 $\mathrm{m}$ diameter) heliotrope balloon. Point A represents the same position on the plastic sheet for each step. Step 1: Unfold each plastic strip into a $12 \mathrm{ft} \times 30 \mathrm{ft}$ rectangle. Step 2: Fold the rectangle across its longest dimension. Step 3: Fold the rectangle across its shortest dimension. Point A is now at the lower-right corner of a doubly folded plastic sheet. Stack all the sheets on top of each other, ensuring that point $\mathrm{A}$ is always in the same position for each. Then draw the gore curve on the topmost sheet and cut along the line [see Eq. (1)]. Step 4: A gore after cutting.

and then taped into place over the top to better distribute stress during launch and flight.

Heliotrope envelopes are open at the bottom to allow inflation but more importantly to vent air as the balloon rises. The $6 \mathrm{~m}$ envelope described above performs well with a bottom hole about $1 \mathrm{~m}$ across. The hole is constructed by first cutting the envelope to the desired size. Then, a loop of strong cord is made with the same diameter as the hole. The lower edge of the envelope is pulled through the loop and then taped to itself. Payload rigging lines can be added by tying loops across the vent hole cord. This is best done at the points were gore tape lines come down and are folded across each other. When deploying heliotropes in midair using a tow balloon (or other means), the bottom must be held open using a rigid hoop instead of flexible cord. We have had success with stiff plastic tubing.

Heliotropes must discharge air through the vent hole as they rise, otherwise the envelope will overpressurize and rupture. Larger balloons will therefore require larger vent holes. Basic physical reasoning suggests that the surface area of the vent hole should scale with envelope volume. A ratio of about $1 \mathrm{~m}^{2}$ of vent-hole surface area to $40 \mathrm{~m}^{3}$ of volume approximately matches the design of our most commonly used balloon.

Once the envelope is complete, we add charcoal powder to the interior to darken it (Fig. 1f). The best material is marketed as "air float charcoal." It is readily available online through pyrotechnics supply shops. Other very fine grained carbon dust sources, such as artist's charcoal powder, can be used but do not tend to stick to the plastic as well as air float does. A poorly darkened balloon does not reach as high an internal temperature as a well-darkened balloon, resulting in a slower ascent rate and lower float level. For example, compare the flights of the poorly darkened "Tortoise" balloon and the well-darkened "Hare" balloon summarized in Table 1.

\section{Launch}

Heliotrope balloons have much lower lift to envelope size ratios than regular hot-air and helium balloons. They also depend on sunlight to fly. Ideal ground launch conditions are cool, sunny days with very low surface winds $\left(<3 \mathrm{~m} \mathrm{~s}^{-1}\right)$. There is generally not enough solar radiation to reliably fly until about a half hour after sunrise. However, heliotropes have been inflated and launched under moderate cirrus cloud cover. We have not attempted to launch balloons when stratus or cumulus cloud shadows are present, but we note that even a thin layer of fog makes a ground launch impossible. The following section will cover both inflation and launch from the ground as well as the use of a helium balloon to tow the heliotrope to a high altitude before releasing it. 
TABLE 1. Balloon parameters, trajectory statistics, and temperatures for seven recent heliotrope flights. The reported masses are for the envelope (left value) and the payload (right value). The reported temperatures are those calculated for the balloon's interior (left value) and the ambient conditions at float altitude via the Global Forecast System (right value). The impact velocity for the Tortoise flight is unknown because tracking was lost prior to landing.

\begin{tabular}{|c|c|c|c|c|c|c|c|c|}
\hline Name & $\begin{array}{l}\text { Diameter } \\
(\mathrm{m})\end{array}$ & $\begin{array}{c}\text { Mass } \\
(\mathrm{kg})\end{array}$ & Launch & $\begin{array}{c}\text { Flight } \\
\text { duration }(\mathrm{h})\end{array}$ & $\begin{array}{c}\text { Ascent } \\
\text { rate }\left(\mathrm{m} \mathrm{s}^{-1}\right)\end{array}$ & $\begin{array}{l}\text { Float } \\
\text { altitude } \\
(\mathrm{km})\end{array}$ & $\begin{array}{c}\text { Impact } \\
\text { speed }\left(\mathrm{m} \mathrm{s}^{-1}\right)\end{array}$ & $\begin{array}{c}\text { Temperature } \\
\left({ }^{\circ} \mathrm{C}\right)\end{array}$ \\
\hline DAG Test & 9.3 & $3.0 / 2.4$ & 1441:39 UTC 10 Oct 2018 & 10.6 & 1.9 & 20.3 & 6.1 & $-8.0 /-61^{\mathrm{a}}$ \\
\hline RedVox II & 5.8 & $1.3 / 1.9$ & 1411:18 UTC 10 Oct 2018 & 10.7 & 1.9 & 19.2 & 8.2 & $36 /-60^{\mathrm{a}}$ \\
\hline Hare & 5.8 & $1.2 / 1.7$ & 1454:01 UTC 22 Jul 2019 & 14.2 & 2.0 & 20.0 & 1.9 & $24 /-61^{b}$ \\
\hline Tortoise & 5.8 & $1.2 / 1.7$ & 1408:33 UTC 22 Jul 2019 & 13.4 & 1.0 & 18.4 & - & $0.33 /-63^{\mathrm{b}}$ \\
\hline Crazy Cat & $8.5^{\mathrm{c}}$ & $3.1^{\mathrm{c}} / 2.3$ & 1609:00 UTC 9 Aug 2019 & 13.6 & 2.4 & 24.1 & 1.2 & $65 /-52^{\mathrm{b}}$ \\
\hline DAG 4 P2 & 5.8 & $1.3 / 0.70$ & 1342:30 UTC 22 Jun 2019 & 16.5 & 2.1 & 23.0 & 1.0 & $68 /-52^{\mathrm{b}}$ \\
\hline DAG 4 P6 & 5.8 & $1.3 / 0.74$ & 1334:12 UTC 22 Jun 2019 & 14.1 & 1.8 & 19.2 & 3.9 & $-6.2 /-57^{b}$ \\
\hline
\end{tabular}

${ }^{\mathrm{a}}$ External and estimated internal temperatures at 1800 UTC.

${ }^{\mathrm{b}}$ External and estimated internal temperatures at 0000 UTC on the day after launch.

${ }^{\mathrm{c}}$ Estimated value.

The inflation site must be clear of anything that can tear the envelope-indeed, most failures to launch have occurred due to snagging. If tarps are used, then they should cover enough area for the balloon to roll in a complete circle without touching anything that could tear it. Large grassy areas (golf courses, football fields, etc.) are ideal. We have even launched off of parking lots, although the asphalt can damage the envelope if it is rough or gravelly. Hangars or other structures can be used as long as the door is large enough to permit the fully inflated balloon to exit without tearing.

We typically use a box fan to inflate the balloon. These fans can be powered using high-wattage car inverters or generators. The balloon is laid out with the opening upwind and the top downwind. The fan is pointed into the opening and air is directed into the balloon. Another inflation method is to simply holding the balloon open and walk back and forth. This "ram inflation" method is not as efficient and requires a large area free of obstructions, but it works well when no other equipment is available. Finally, heliotropes were launched in windy conditions $\left(5 \mathrm{~m} \mathrm{~s}^{-1}\right)$ by injecting heated air into the envelope inside a hangar, then swiftly bringing the balloons outside. While the balloons were difficult to control during release, they did remain positively buoyant and the launches were successful.

In ideal conditions (strong sun, low wind), the heliotrope envelope will lift off the ground several minutes after inflation starts, and be able to pick up over a kilogram a minute or two later. Indeed, a team of two can launch a balloon every 5 to $10 \mathrm{~min}$ when this is the case (Bowman and Albert 2018). When winds are higher, sunlight is less strong and/or payloads are heavier, it may be necessary to walk or run while holding the payload after the envelope achieves positive lift. This allows the balloon to continue heating and take off, but depending on the wind strength this may result in a runout of several hundred meters. Figure 3 shows a heliotrope being inflated, walked, and released.

In rare occasions, a heliotrope will take off and then land a few tens of seconds later. If the payload is caught and held for a brief time, the balloon will regain lift and continue to ascend. It is important to walk or run beneath a balloon for a few minutes after release in case this occurs. This issue typically occurs when sunlight is weak (e.g., just after sunrise) and/or the balloon has a heavy payload.

Another option is to tow the heliotrope up to altitude using a standard meteorological balloon. This permits solar hot-air balloon deployment under cloud cover and/or higher winds. We attach the meteorological balloon to a loop of cord inside the top of the heliotrope and then run lines from this loop out through the envelope. The meteorological balloon is attached a meter or two above the heliotrope. The bottom of the heliotrope is held open by using a loop of stiff plastic tubing instead of cord as mentioned in section 3. When the meteorological balloon bursts, the solar hot-air balloon ram inflates as it falls. Eventually, the heliotrope heats up enough to sustain its own weight, and it maintains that elevation until sunset.

\section{Flight stages}

A heliotrope balloon flight consists of an ascent phase, a float (neutral buoyancy) phase, and a descent phase. The length and properties of each phase depends on the size of the balloon, the weight of the payload, the 


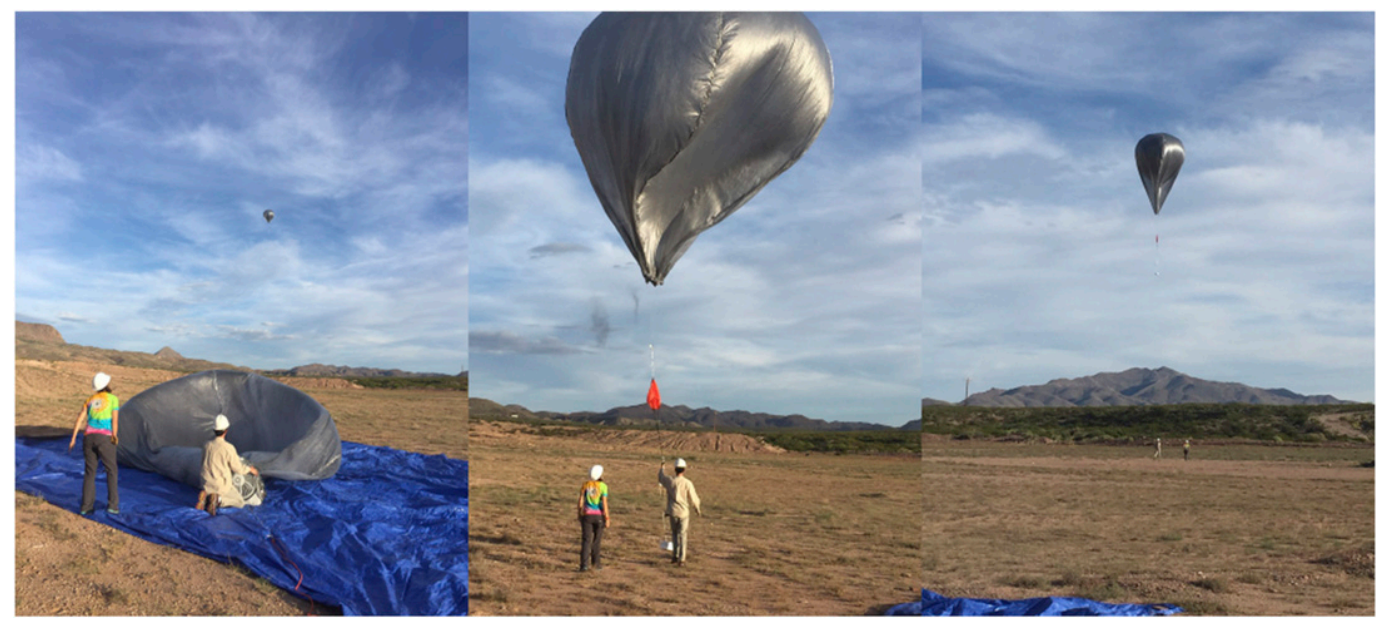

FIG. 3. (left) Inflating a $6 \mathrm{~m}$ heliotrope with a box fan, (center) walking the inflated envelope across an open area until it gains sufficient lift to pick up the payload, and (right) a successful launch.

time of year, and the absorptive properties of the balloon envelope, among others. Figure 4 shows trajectories of seven heliotropes launched from the ground in various locations and dates, and Fig. 5 shows the behavior of heliotropes towed aloft using a meteorological balloon. The latitude, longitude, and altitude of the balloons were determined using onboard GPS receivers.

\section{a. Ascent}

Heliotropes tend to ascend slowly after launch, reaching a maximum rise rate at approximately two-thirds of their float elevation, and slowing back down thereafter (Fig. 6). The rise rate often oscillates with amplitudes up to a meter per second, which is a behavior seen in lift gas balloons as well (Anderson and Taback 1991). Heliotrope ascent rates can drop slightly once they reach several hundred meters above the ground, perhaps because of less thermal radiation from the surface of Earth and/or cooling as they transition into stronger horizontal winds above the planetary boundary layer.

Ascent rate appears related to the configuration of the balloon, although it is unclear which factors are the most influential. For example, Fig. 6 shows two balloons, designated Tortoise and Hare, launched within a few tens of minutes of each other from the same location. Tortoise had been rather poorly darkened with artist's charcoal powder while Hare had been well pigmented with air float charcoal. The effect on ascent rates is striking: Tortoise ascended about $1 \mathrm{~m} \mathrm{~s}^{-1}$ slower than Hare. The DAG 4 P2 and DAG 4 P6 weighed the nearly same and were both darkened using air float charcoal, yet showed a divergent ascent rate above about $10 \mathrm{~km}$.

\section{b. Float}

When a heliotrope reaches neutral buoyancy, it begins a relatively level flight phase. This float level is reached

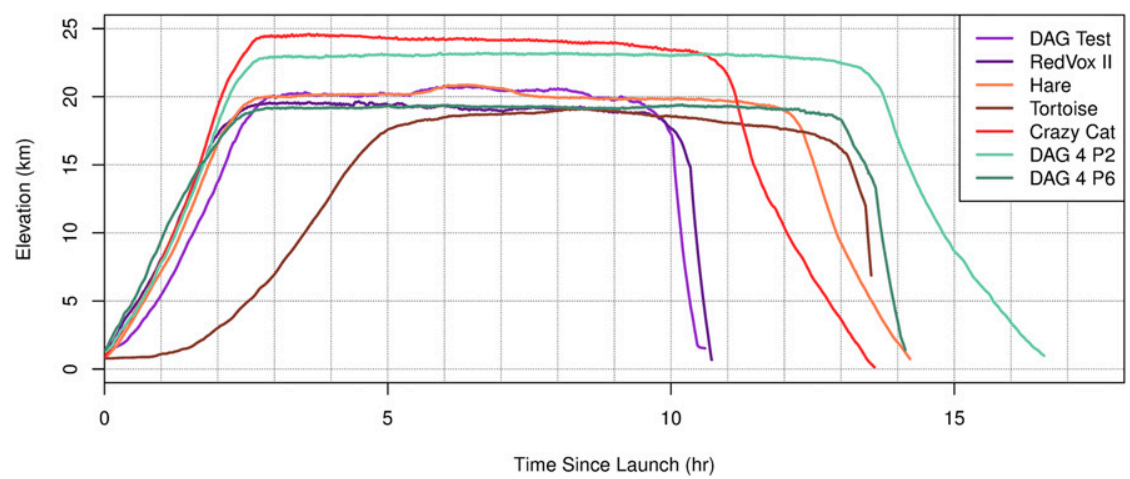

FIG. 4. Launch-to-landing sequence for seven heliotrope balloons inflated and launched on the ground. The traces have been aligned with the time of launch to provide a standard reference, but they have not been adjusted for ground elevation. The length of time each balloon was in flight depends on the timing of sunset on launch day and the descent velocity. 


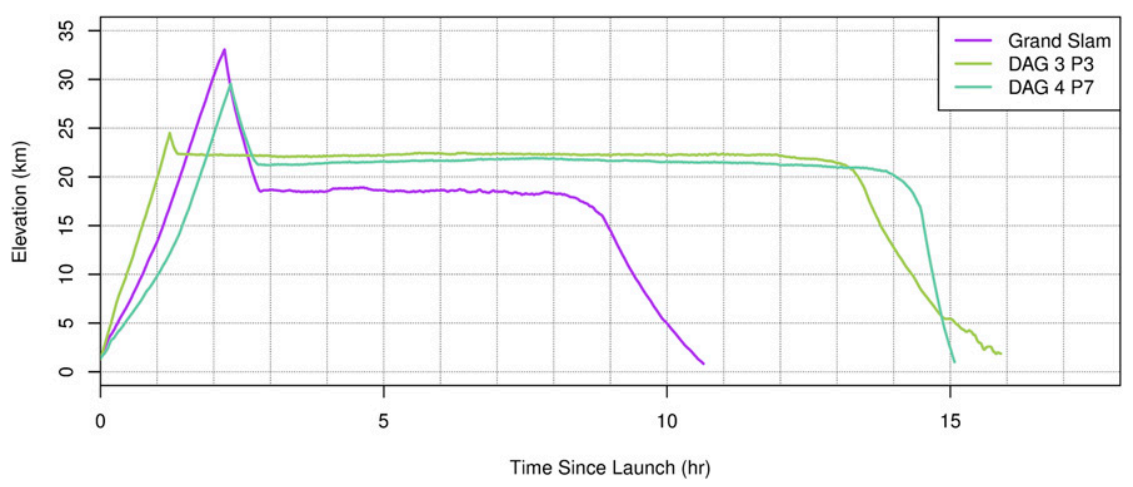

FIG. 5. Launch to landing sequence for three heliotrope balloons towed aloft using heliumfilled meteorological balloons. The traces have been aligned with the time of launch to provide a standard reference, but they have not been adjusted for ground elevation.

from below on ground launched heliotropes (Fig. 4), and from above when it has been released from a tow balloon (Fig. 5). The float altitude may remain steady, decrease slightly as the flight progresses, or experience hour-scale upward excursions; virtually identical balloons launched at nearly the same time can exhibit any combination of these behaviors. However, the float elevation typically remains within a range of about a kilometer. Float elevation decreases slightly about an hour before sunset, transitioning to the descent phase once the balloon falls into shadow.

During the float phase, heliotropes experience episodes of vertical oscillations with amplitudes of several tens of meters (Fig. 7). This represents a resonant mode that is observed on superpressure and zero-pressure helium balloons as well, where it is always slightly shorter than the local Brunt-Väisälä period (Vincent and Hertzog 2014; Quinn and Holzworth 1987).

As noted in Anderson and Taback (1991), zeropressure helium balloons are expected to oscillate in a nonlinear manner because they can release gas through their vent holes via one-way check valves. Heliotropes are likely even more nonlinear than zero-pressure balloons because they can also ingest air with each oscillation cycle. Indeed, the saw-tooth pattern in the spectrogram shown in Fig. 7 is diagnostic of frequency modulation (Bowman and Lees 2013). The driver behind this motion is likely atmospheric gravity waves, which also perturb zero-pressure and superpressure balloon trajectories (Quinn and Holzworth 1987; Schoeberl et al. 2017). Indeed, Bowman and Albert (2018) report that the magnitude and period of horizontal deflections recorded on heliotrope flights match those induced on radiosondes by gravity waves at similar elevations and latitudes. However, we stress that heliotrope altitude oscillations are a poor proxy for vertical atmospheric motion due to the nonlinearities mentioned above; in fact, even superpressure balloons are unreliable especially at short periods (Nastrom 1980).

Heliotrope altitude oscillations can be an asset, a liability, or completely irrelevant depending on the goal of the flight. If the intent is to measure the fine structure of the upper troposphere or the lower stratosphere, this behavior naturally allows a number of transects across a

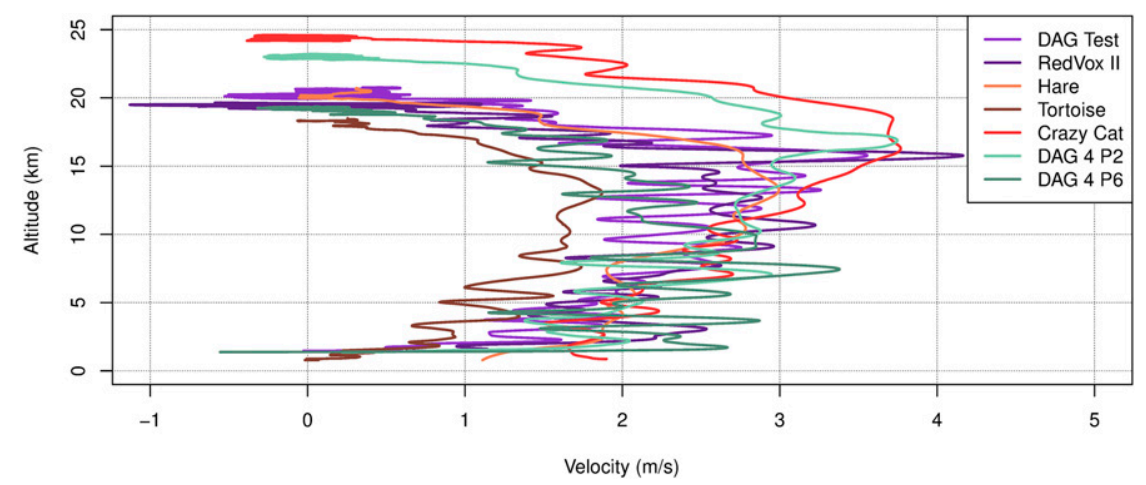

FIG. 6. Ascent velocities for the seven ground-launched heliotrope balloons shown in Fig. 4. 

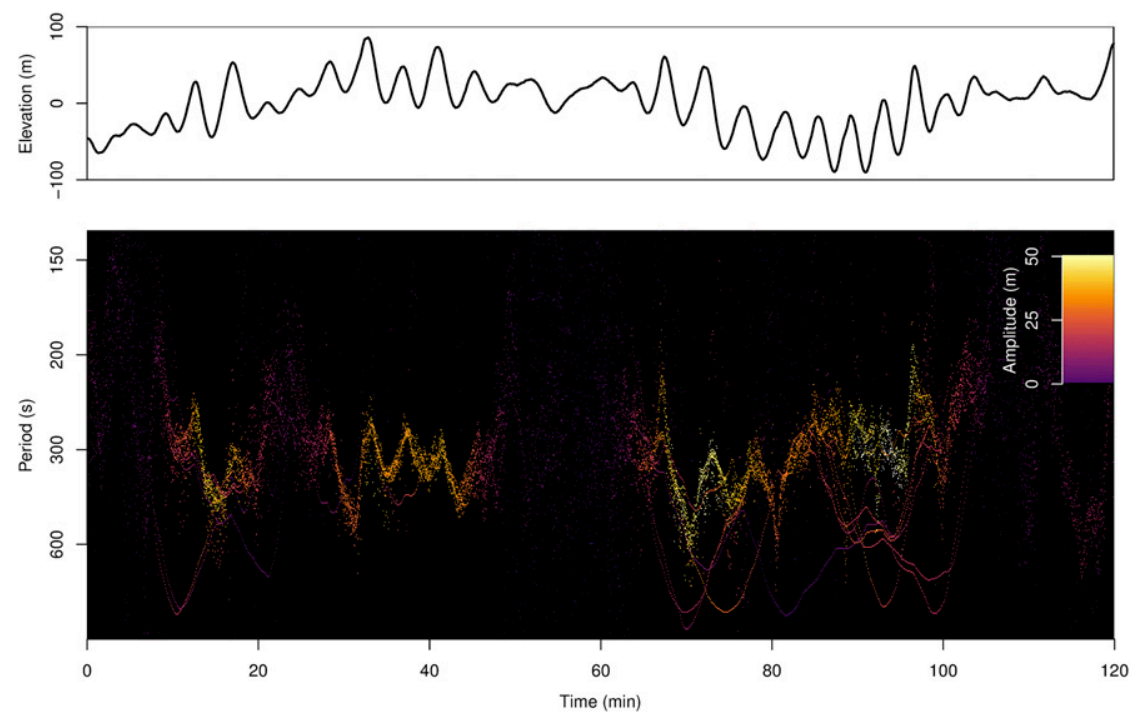

FIG. 7. Ensemble Hilbert spectrogram of vertical oscillations experienced during float on a $10 \mathrm{~m}$ heliotrope (see section $5 \mathrm{~b}$ ). These sporadic, nonlinear oscillations likely arise from the balloon's response to atmospheric gravity waves.

very small region of interest. However, the oscillations can be inconvenient when attempting to record acoustic signals with periods of greater than $10 \mathrm{~s}$, because the nonlinear nature of the pressure fluctuations bleeds spectral energy into the band of interest [see the differences between heliotrope and zero-pressure balloon infrasound spectra reported in Young et al. (2018)]. If the intent is simply to test hardware in a near-space environment, then the fluctuation does not positively or negatively affect the mission goals. The vertical motion of the balloon may create a turbulent wake, and the discharge of air from the vent hole could perturb certain measurements (e.g., temperature, wind speed) on a payload attached to a very short tether. If this is a concern, sensors can be placed on the end of a long flight train to isolate them-we have successfully launched instrumentation strings nearly $40 \mathrm{~m}$ from end to end.

\section{c. Descent}

Heliotropes descend rapidly after sunset, but the manner of this fall can vary even between nearly identical balloons (Fig. 8). In one case, balloons descend about $4 \mathrm{~m} \mathrm{~s}^{-1}$ in the $15-20 \mathrm{~km}$ range, with the drop rate decreasing to $1-2 \mathrm{~m} \mathrm{~s}^{-1}$ by landing. In the other case, the descent rate abruptly increases by as much as $10 \mathrm{~m} \mathrm{~s}^{-1}$ and then slows gradually to $5-7 \mathrm{~m} \mathrm{~s}^{-1}$ by impact. The bimodal nature of heliotrope descent suggests that the envelope may become deflated in some cases, resulting in much faster speeds. This includes balloons with and without parachutes, indicating that it is the state of the envelope rather than the size of the balloon that governs the descent rate. Turbulence or severe wind shear may be responsible for balloon deflation events. Intermittent turbulence may explain why DAG 4 P6 sped up dramatically at about $13 \mathrm{~km}$ altitude but DAG 4 P2 (a virtually identical flight system) maintained a relatively steady descent rate.

\section{d. Landing}

Heliotrope impact speeds are typically less than $10 \mathrm{~m} \mathrm{~s}^{-1}$, even when no parachute is included (Table 1). This is likely because the envelope is at least partially inflated during final descent. The fate of the balloon and its payload after landing strongly depends on the wind speeds and terrain type. The envelope quickly becomes snagged or ripped apart most of the time (see Fig. 9). However, landing in windy conditions and open terrain may cause the flight system to be dragged a considerable distance. This is because the envelope acts as a sail, easily pulling the payload behind it until either the plastic is snagged or the payload string breaks. Despite this, payloads usually escape serious injury. However, objects at the bottom of a long flight train have become damaged due to impact and subsequent dragging. It may be worth developing a payload release mechanism to prevent this from happening in future flights.

\section{Trajectory prediction}

It is often necessary to predict the flight path of a balloon to comply with airspace regulations, achieve 


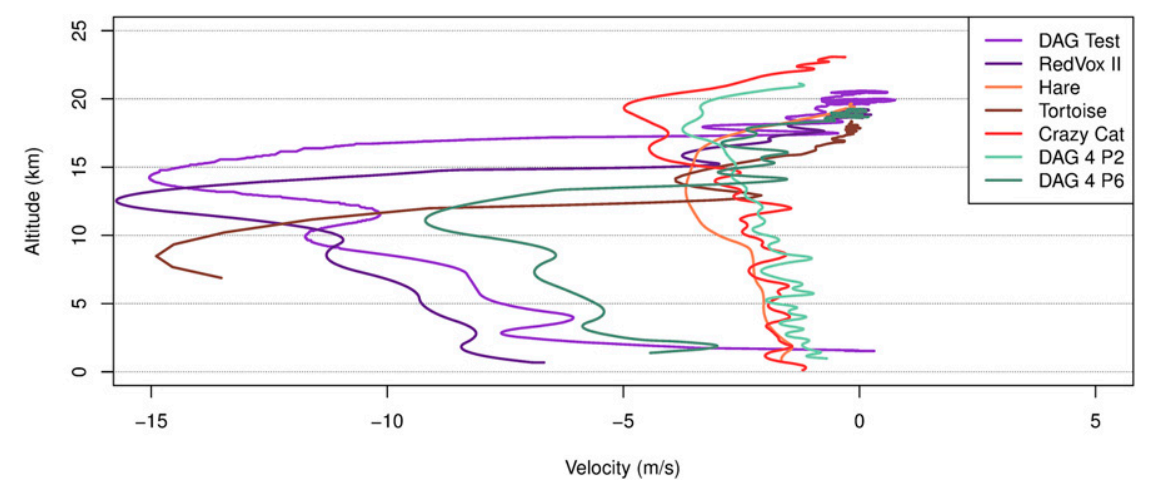

FIG. 8. Descent velocities for the seven heliotrope balloons shown in Fig. 4.

mission objectives, and ensure that the payload lands in an accessible location. However, trajectory prediction is a difficult problem that requires precise knowledge of the atmospheric state (e.g., ambient temperature, pressure, and winds from the ground surface to tens of kilometers), the radiative properties of the flight region (e.g., albedo, cloud factor, upwelling/downwelling radiation), and absorptivity/emissivity of the balloon envelope (Garg and Emami 2019). The last point in particular is difficult for the heliotrope balloon, because the envelope material and darkening powder characteristics are not well known.

Instead of predicting a single balloon's flight path, we developed a stochastic model that attempts to constrain the behavior of an ensemble of heliotropes with different ascent rates and float altitudes. The model output consists of many different trajectories, each showing a possible flight path that could occur if a balloon were launched from a particular point at a given time. The horizontal wind field is derived from the $0.5^{\circ}$ Global Forecast System weather model via rNOMADS (Bowman and Lees 2015). The wind fields at each model grid point are linearly interpolated in time to yield values for every moment of the balloon flight.

Ascent models for ground-launched heliotropes are selected from one of four actual climbouts of nearly identical $6 \mathrm{~m}$ balloons. Maximum vertical velocity and float altitudes are selected from a range of possible values, then scaled by the expected maximum ascent rate. For example, a model run might request 100 trials of ascent trajectories with a maximum ascent-rate altitude between 12 and $16 \mathrm{~km}$ and a float altitude between 18 and $25 \mathrm{~km}$, with maximum ascents between 2 and $4 \mathrm{~ms}^{-1}$. Ascent models for towed heliotrope launches select from a range of plausible climb rates, release altitudes, and postdrop descent speeds $\left(3-5 \mathrm{~m} \mathrm{~s}^{-1}, 22-26 \mathrm{~km}\right.$, and $4-7 \mathrm{~m} \mathrm{~s}^{-1}$, for example). Once at float, the simulated balloon remains at a constant altitude until sunset. After sunset, the balloon is assumed to descend fully inflated at terminal velocity.

A comparison between predicted and actual heliotrope trajectories is shown in Figs. 10 and 11. Two balloons were launched as part of this campaign. One of the balloons followed a path that was generally consistent with the simulated trajectories and landed $2 \mathrm{~km}$ away from one of the predicted impact points. The other balloon's trajectory remained inside the cluster of simulated trajectories, but the actual flight was much more westerly and resulted in a landing point very far from those predicted by the model (over $130 \mathrm{~km}$ ).

The trajectory model described above is simple and entirely empirical. It relies on a handful of balloon ascents from a single location on a single day. Despite this, it is able to predict the general area occupied by the balloons, and gives a sense of their expected behavior. Future upgrades to this model could include a more physics-based approach; with the inclusion of the appropriate uncertainty in input parameters this may give a clearer picture of the range of possible balloon behaviors for a certain launch location and time. Garg and Emami (2019) also describe a semiempirical regression approach that may be appropriate with the large dataset of heliotrope flights that have been accumulated over the past few years. In the short term, we

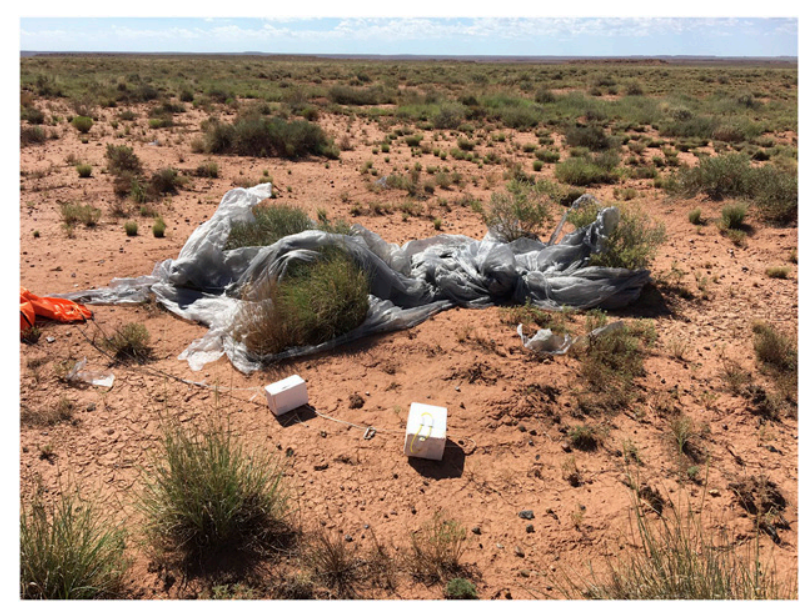

FIG. 9. A $6 \mathrm{~m}$ heliotrope balloon after landing in the Arizona desert. 


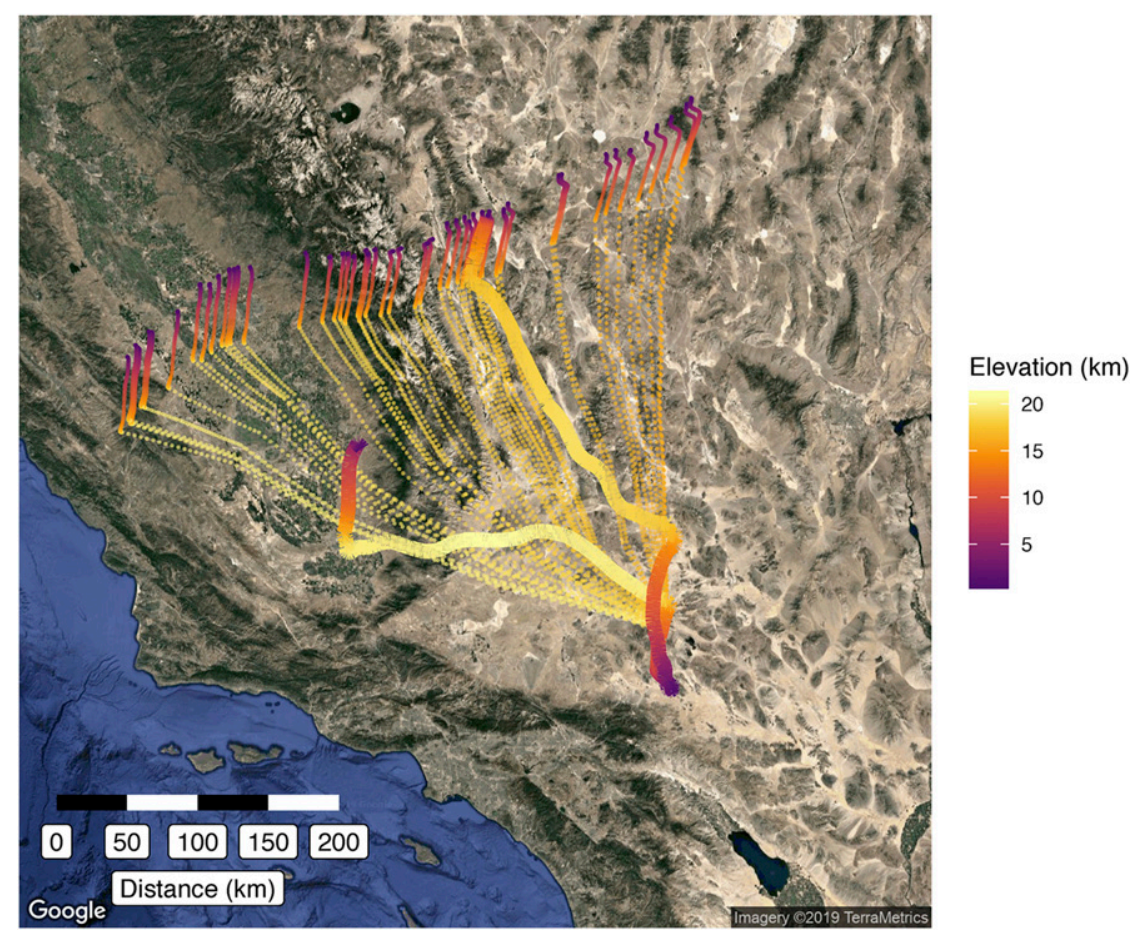

FIG. 10. Predicted trajectories (dots) and actual trajectories (lines) for a heliotrope campaign on $22 \mathrm{Jul} 2019$.

intend to upgrade our code to utilize the $0.25^{\circ} \times 0.25^{\circ}$ Global Forecast System model with cubic spline interpolation in space in time as described in Dharmalingam et al. (2019).

\section{Observed variations in heliotrope flight performance}

A baseline dataset of seven recent heliotrope flights is provided in Table 1. The size and mass of the balloon envelopes are shown, along with the payload mass, launch time, mean ascent rate, mean float altitude, and impact speed. The internal temperature of the balloon is estimated using its known mass and volume along with ambient pressure and temperature values from analysis runs of the Global Forecast System via

$$
T_{i}=\left(\frac{1}{R}\right) \frac{P V m_{n}}{m_{d}-m_{b}}
$$

where $T_{i}$ is internal temperature, $R$ is the universal gas constant, $P$ is ambient pressure, $V$ is balloon volume, $m_{n}$ is the molar mass of dry air, $m_{d}$ is the mass of air displaced by the balloon, and $m_{b}$ is the mass of the envelope and payload. The mass of displaced air is calculated from

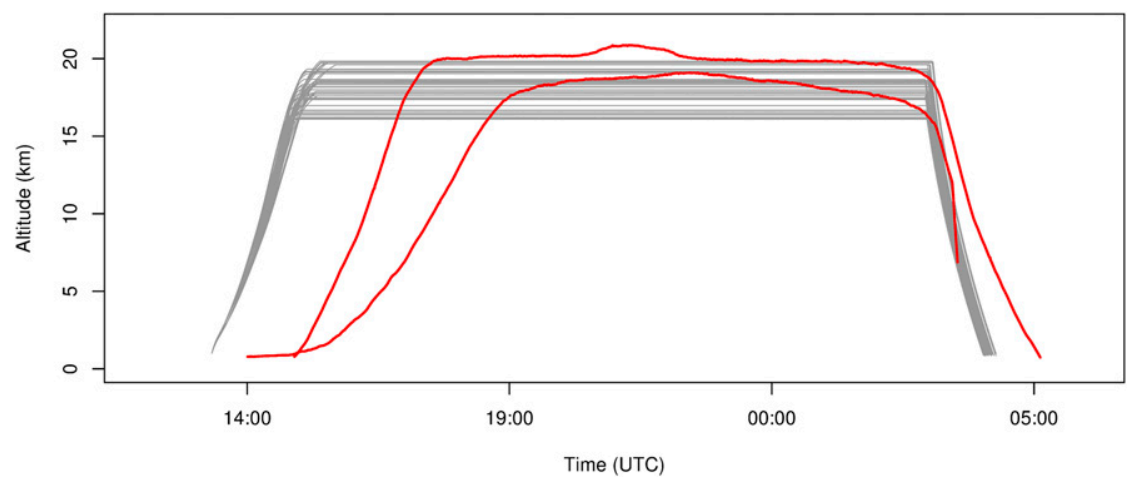

FIG. 11. Time-altitude plot of predicted trajectories (black) and actual trajectories (red) for a heliotrope campaign on 22 Jul 2019. 


$$
m_{d}=m_{n}\left(\frac{P V}{R T_{a}}\right)
$$

where $T_{a}$ is the ambient temperature of the air surrounding the balloon.

As mentioned in earlier sections, balloons with very similar weights launched from the same location within minutes of each other can exhibit different ascent rates and float altitudes. The contrast between the Tortoise and Hare balloons is due to the poor performance of the artist's charcoal powder used to darken the former compared to the air float charcoal applied to the latter. This resulted in a $2 \mathrm{~km}$ altitude difference at float, with Tortoise having an internal temperature around $0^{\circ} \mathrm{C}$ and Hare at $24^{\circ} \mathrm{C}$.

Other differences are more puzzling. The DAG $4 \mathrm{P} 2$ and DAG 4 P6 balloons and payloads were virtually identical; they were built by the same team, were the same size, were launched $8 \mathrm{~min}$ apart from the same location, and differed in mass by only $40 \mathrm{~g}$. However, one floated nearly $4 \mathrm{~km}$ higher than the other, with a resulting temperature contrast of over $70^{\circ} \mathrm{C}$ between them. The most likely culprit is that the DAG 4 P6 balloon envelope was damaged in some way. The abrupt ascent-rate divergence around $10 \mathrm{~km}$ shown in Fig. 6 points to a possible rip opening in the envelope, creating a slow vent that did not allow DAG 4 P6 to maintain a high-enough internal temperature. This could be due to either clear-air turbulence (observed terminating a flight in 2018) or envelope overpressurization leading to failure (presumed cause of a termination in 2019).

The excellent performance of the Crazy Cat balloon (24.1 km average float) was very surprising in light of the relatively low altitude ( $20.3 \mathrm{~km}$ average float) reached by the similar-sized DAG Test balloon a year before. In this case, it is more likely that the DAG Test envelope was damaged during launch. An unexpected wind gust shifted the envelope about during inflation and caused it to roll off the ground cloth. It is possible a small hole was formed at this time.

Other campaigns have had five balloons behave in a consistent manner. This underscores the need for identical darkening and construction techniques to be used for the same set of balloons. Once built, envelopes should be carefully inspected for holes prior to flight—especially if they have been assembled by an inexperienced team. Careful attention should be paid to the size of the vent hole, and launches should not be performed on days when clear air turbulence is likely. During launch, enough tarps should be laid down to permit the balloon to rotate a full $360^{\circ}$ without touching objects that may snag it.

\section{Physics of solar balloon flight}

Hot-air balloons are seldom used for scientific missions, and those that rely on passive solar heating are rarer still. As a consequence, much of the literature describing the physics of balloon flight pertains to those using lift gas rather than ambient air. Of those that discuss hot-air balloons, likely very few consider the behavior of these flight systems in the lower stratosphere. Accordingly, this section describes the physics of solar hot-air balloons, outlining the various sources and sinks of energy that determine the ascent, float altitude, and eventual descent of the flight system. Future researchers may find this useful in designing their own balloons or developing a physics-based trajectory model.

The heliotrope balloon consists of a dark-colored spherical envelope with an opening at the bottom, filled with ambient air. The envelope absorbs sunlight and heats the air inside, fulfilling the role of a burner in a traditional hot-air balloon. Heliotrope ascent rate and float elevation is determined by the difference in air density inside and outside of the balloon, which is a function of internal versus external temperature in this case. The internal temperature of the balloon is itself a function of heat transfer due to absorbed/emitted radiation and fluid flow. For purposes of discussion we will consider a spherical balloon experiencing conditions typical of midsummer in New Mexico (see Table 2). The following discussion is meant to be an introduction to the physics of solar balloon flights; specific assumptions made below will be evaluated in more detail in future studies aimed at improving heliotrope trajectory prediction.

\section{a. Heat input from incident radiation}

Solar balloons depend entirely on radiation input to the envelope to fly (Fig. 12). This energy originates from the following:

- Direct solar radiation

- Reflected solar radiation from Earth's surface or clouds

- Diffuse solar radiation scattered by the sky

- Infrared radiation emitted by Earth or clouds

- Infrared radiation emitted by the sky

\section{1) DIRECT SOLAR RADIATION}

On a given day of the year, the intensity of solar radiation reaching Earth is (Farley 2005)

$$
I_{S, 0}=1358\left\{1+\frac{1}{2}\left[\left(\frac{1+e}{1-3}\right)^{2}-1\right] \cos \theta\right\},
$$

where $e$ is the orbital eccentricity (0.016708) and $\theta$ is the true anomaly,

$$
\theta=\frac{\mathrm{DOY}}{365}
$$


TABLE 2. Baseline balloon, atmospheric, and launch conditions.

\begin{tabular}{lc}
\hline \hline Date & $25 \mathrm{Jul} 2017$ \\
Latitude & $34.071^{\circ} \mathrm{N}$ \\
Diameter $D$ & $6 \mathrm{~m}$ \\
Effective envelope radiation absorptivity $\bar{\alpha}_{\text {eff }}$ & 0.9 \\
Ground temperature $T_{e}$ & $315 \mathrm{~K}$ \\
Ground albedo & 0.2 \\
Ground emissivity & 0.95 \\
Cloud fraction $C_{f}$ & 0.0 \\
Surface pressure & $856 \mathrm{hPa}$ \\
\hline
\end{tabular}

and DOY is approximately the number of days since aphelion (3 January). The amount of this solar radiation that reaches a balloon within Earth's atmosphere is determined by the atmospheric transmittance

$$
I_{S}=\tau_{\mathrm{atm}} I_{S, 0}
$$

where (Kreith and Kreider 1974)

$$
\tau_{\mathrm{atm}} \approx 0.5\left(e^{-0.65 m_{a}}+e^{-0.095 m_{a}}\right) .
$$

The $m_{a}$ term is the mass of air between the balloon and the sun. Its value at a given elevation in the atmosphere is

$$
m_{a}=\frac{P(z)}{P_{0}}\left[\sqrt{1229+(614 \cos \zeta)^{2}}-614 \cos \zeta\right],
$$

where $P(z)$ is the pressure at a given elevation, $P_{0}$ is pressure at sea level, and $\zeta$ is the solar zenith angle.

\section{2) DifFuse AND REFLECTED SUNLIGHT}

Energy can also reach the balloon from diffuse atmospheric reflection and Earth surface/cloud reflection. Diffuse radiation from the sky is approximately (Dai et al. 2012)

$$
I_{S, \mathrm{sky}}=\left[\frac{1}{2} I_{0} \sin (\pi / 2-\zeta) \frac{1-\tau_{\mathrm{atm}}}{1-1.4 \ln \tau_{\mathrm{atm}}}\right] .
$$

The reflected solar radiation is

$$
I_{S, \text { reflected }}=A I_{S} \sin (\pi / 2-\zeta),
$$

where $A$ is Earth albedo (Farley 2005). Kreith and Kreider (1974) gives average albedo measurements versus latitude under different weather conditions. On an average day at $\sim 40^{\circ} \mathrm{N}$ latitude the albedo is 0.4 ; however, the albedo can vary with weather conditions ( 0.2 for clear skies to 0.6 for overcast skies). To account for cloud coverage, we estimate the totally obscured fraction of the sky $C_{F}$ and then follow the albedo expression used by Farley (2005):

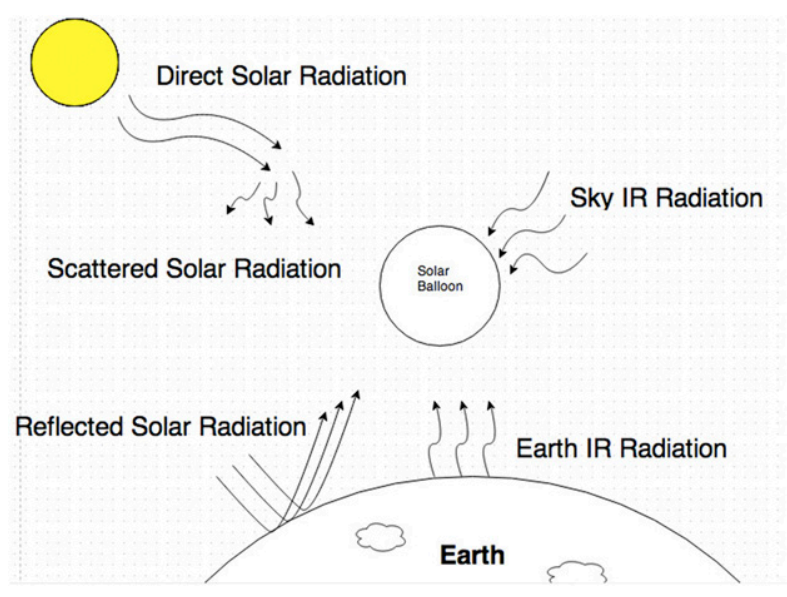

FIG. 12. Radiation sources that contribute to solar hot-air balloon envelope heating.

$$
A= \begin{cases}A_{\text {ground }}\left(1-C_{F}\right) & \text { below clouds } \\ A_{\text {ground }}\left(1-C_{F}\right)^{2}+A_{\text {cloud }}\left(C_{F}\right) & \text { above clouds }\end{cases}
$$

where we always take $A_{\text {cloud }}=0.6$. Figure 13 shows a comparison of the radiation intensity from different sources on a clear day at sea level and $20000 \mathrm{~m}$. The direct solar radiation is always higher than the diffuse and reflected radiation, and all three peak at noon. As shown in Fig. 13b, the diffuse radiation is nearly zero at $20000 \mathrm{~m}$ because there is not enough atmosphere to scatter light above this elevation (the sky above is visibly black at these elevations). The direct solar radiation at $20000 \mathrm{~m}$ is nearly equal to $I_{0}$, the intensity of the sun above the atmosphere.

\section{3) INFRARED RADIATION FROM EARTH AND SKY}

Next, we consider the infrared radiation emitted by the ground and the atmosphere. Earth can be modeled as a graybody that emits radiation according to

$$
I_{\mathrm{IR}, \mathrm{E} 0}=\varepsilon_{\mathrm{Earth}} \sigma_{\mathrm{SB}} T_{e}^{4},
$$

where $\varepsilon_{\text {Earth }}$ is the emissivity of Earth (on average 0.95 , but can be as low as 0.8 in some regions; Farley 2005), $\sigma_{\mathrm{SB}}$ is the Stefan-Boltzmann constant, and $T_{e}$ is the effective temperature of Earth. To account for cloud coverage, $T_{e}$ is modified via the approximation (Dai et al. 2012)

$$
T_{e}=\left(1-C_{F}\right) T_{g}+C_{F} T_{c}
$$

where $T_{g}$ is the temperature of the ground surface and $T_{c}$ is the temperature of the top of the clouds. In a similar manner to incident solar radiation, only a fraction of the IR 

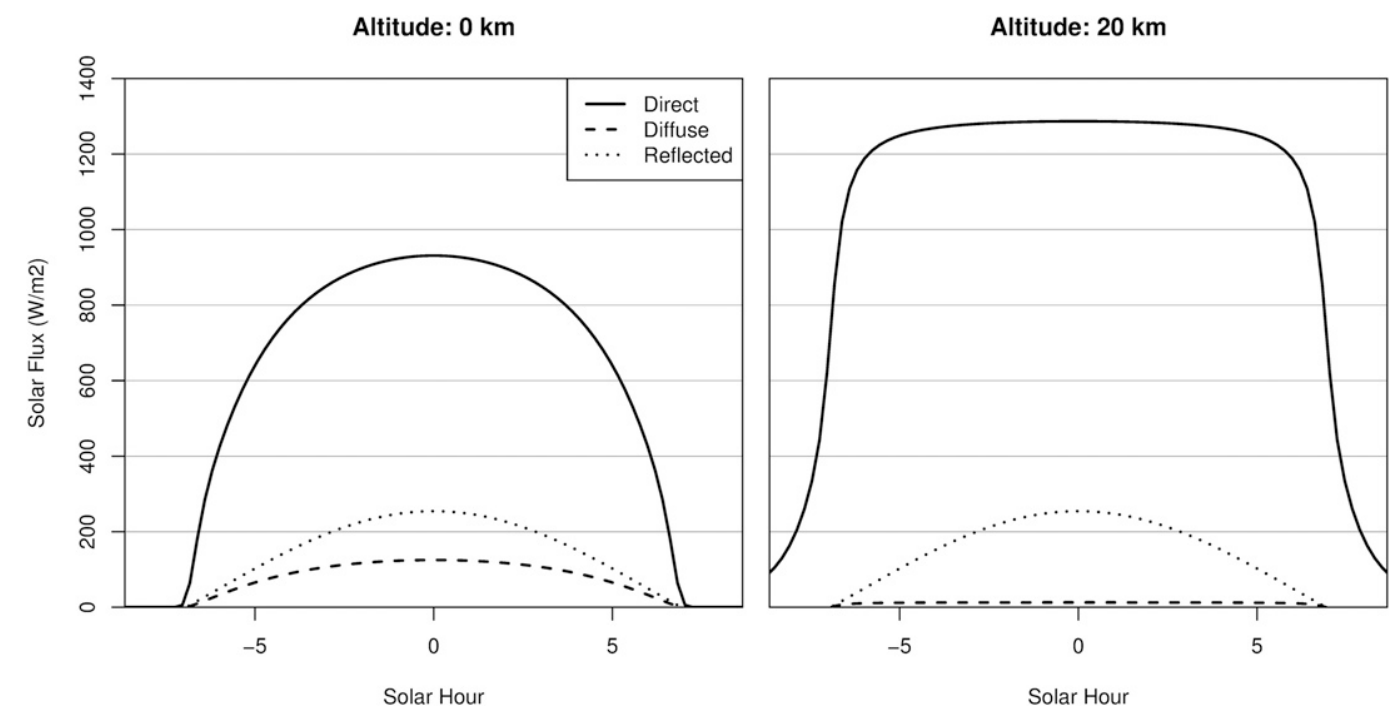

FIG. 13. Direct, diffuse, and reflected solar flux vs solar hour for the ground surface and $20 \mathrm{~km}$ for conditions listed in Table 2.

radiation emitted from Earth is transmitted through the atmosphere. IR transmittance $\tau_{\text {IR }}$ is given by Farley (2005):

$$
\tau_{\text {IR }}=1.716-0.5\left[e^{-0.65 P(z) / P_{0}}+e^{-0.095 P(z) / P_{0}}\right] .
$$

(Note: we have corrected the typo in the expression by Farley $-0.95 \rightarrow-0.095)$. The IR radiation from Earth at elevation is then given by

$$
I_{\mathrm{IR}, \mathrm{Earth}}=\tau_{\mathrm{IR}} I_{\mathrm{IR}, \mathrm{E} 0} .
$$

The IR radiation from the sky is more difficult to quantify. Kreith and Kreider (1974) recommend using local experimental measurements from radiometers, or lieu of this parameterized values from nearby latitudes. We use a simple fit of Fig. 17 in Kreith and Kreider (1974) between $40^{\circ}$ and $50^{\circ}$ latitude:

$$
I_{\mathrm{IR}, \mathrm{sky}}=\max [-0.03 \times(\text { elevation })+300,50],
$$

which is $300 \mathrm{~W} \mathrm{~m}^{-2}$ at sea level and drops to $50 \mathrm{~W} \mathrm{~m}^{-2}$ at higher elevations. Given the simple nature of this expression we do not modify for cloud coverage (which would only have an effect below the elevation of clouds). An IR radiation temperature can be given by the expression

$$
T_{\mathrm{IR}}=\left(I_{\mathrm{IR}} / \sigma_{\mathrm{SB}}\right)^{1 / 4} \text {. }
$$

The average IR radiation flux on a sphere at ground level should be around $350 \mathrm{~W} \mathrm{~m}^{-2}$, which gives $T_{\mathrm{IR}}=280 \mathrm{~K}$. The infrared temperature at ground level is at or slightly below the temperature of Earth, so this does not significantly affect the temperature of the balloon at launch.
However, at higher elevations $(10-30 \mathrm{~km})$ the atmospheric temperature drops below the IR temperature. This means that it is possible for a balloon to remain above ambient atmospheric temperatures at these elevations using the infrared heating from Earth, which is present at night. This has been exploited by the MIR balloons, which are able to fly at night at altitudes of $20-25 \mathrm{~km}$, and have remained aloft for periods of 60 days (Malaterre 1993)

\section{b. Radiation absorption/emission}

The amount of radiation adsorbed depends on the properties of the balloon film. Radiation striking the balloon can adsorb, reflect, or transmit through the balloon film, and some transmitted radiation can undergo multiple reflections within the balloon. Further complicating matters is the fact that the absorptivity/transmittance/reflectivity of a material typically varies with the angle at which radiation strikes it. We will assume that materials can be modeled by their average film properties (averaged over all incident light angles, denoted by $\bar{x}$ ). The absorptivity, transmittance, and reflectivity any material sum to unity:

$$
\bar{\alpha}+\bar{\tau}+\bar{r}=1 .
$$

To account for multiple internal reflections, we use the expression for effective reflectance from Farley (2005):

$$
\bar{r}_{e}=\bar{r}+\bar{r}^{2}+\bar{r}^{3}+\bar{r}^{4}+\ldots
$$

The total fraction of radiation adsorbed $\bar{\alpha}_{\text {eff }}$ is the given by the sum of directly adsorbed radiation, the transmitted 
times absorbed radiation, and transmitted times (multiply) reflected times absorbed radiation (Farley 2005):

$$
\bar{\alpha}_{\text {eff }}=\bar{\alpha}+\bar{\alpha} \bar{\tau}+\bar{\alpha} \bar{\tau} \bar{r}_{e} .
$$

The heat flux to the surface is then

$$
q_{\mathrm{rad}}=\bar{\alpha}_{\mathrm{eff}} I_{\mathrm{rad}}
$$

and the overall power input is

$$
\dot{Q}_{\mathrm{rad}}=\int_{\text {surf }} \bar{\alpha}_{\text {eff }} I_{\text {rad }}(\Omega) d \Omega
$$

The absorptivity of a material varies with the wavelength of the incident radiation. We will assume that all types of radiation (direct/reflected/diffuse solar and infrared Earth/sky) absorb, transmit, and reflect equally on the balloon film. For baseline balloon model in Table 2, we use a slightly transparent black balloon with $\bar{\alpha}_{S}=\bar{\alpha}_{\mathrm{IR}}=0.8, \bar{\tau}_{S}=\bar{\tau}_{\mathrm{IR}}=0.1$, and $\bar{r}_{S}=\bar{r}_{\mathrm{IR}}=0.1$. The balloon also emits radiation according to

$$
q_{r, e}=\varepsilon_{\mathrm{env}} \sigma_{\mathrm{SB}} T_{\mathrm{env}}^{4} .
$$

We apply Kirchoff's law (assuming the balloon is in thermal equilibrium with its surroundings), which equates the IR absorptivity and emissivity of the envelope $\left(\alpha_{\mathrm{IR}}=\varepsilon_{\text {envelope }}\right)$. Different sources of radiation fall upon different parts of the surface area of the balloon. Direct solar radiation hits the projected area:

$$
A_{\text {proj }}=\pi r^{2},
$$

where $r$ is the radius of the balloon, assuming it is a sphere. The fraction of the surface of the balloon illuminated by radiation originating from Earth is given by the view factor $V_{F}$ (Farley 2005):

$$
V_{F}=\frac{1-\cos \left(\theta_{\mathrm{HC}}\right)}{2},
$$

where $\theta_{\mathrm{HC}}$ is the half-cone angle made by the balloonEarth system:

$$
\theta_{\mathrm{HC}}=\arcsin \left(\frac{R_{\text {Earth }}}{R_{\text {Earth }}+z}\right)
$$

where $R_{\text {Earth }}=6371 \mathrm{~km}$, and $z$ is the balloon elevation. The view factor is 0.5 at sea level and decreases with elevation. Radiation originating from the sky has falls upon the fraction of the surface $\left(1-V_{F}\right)$. The net power input to the balloon due to radiation, $\dot{Q}_{\text {rad }}(W)$, is given by

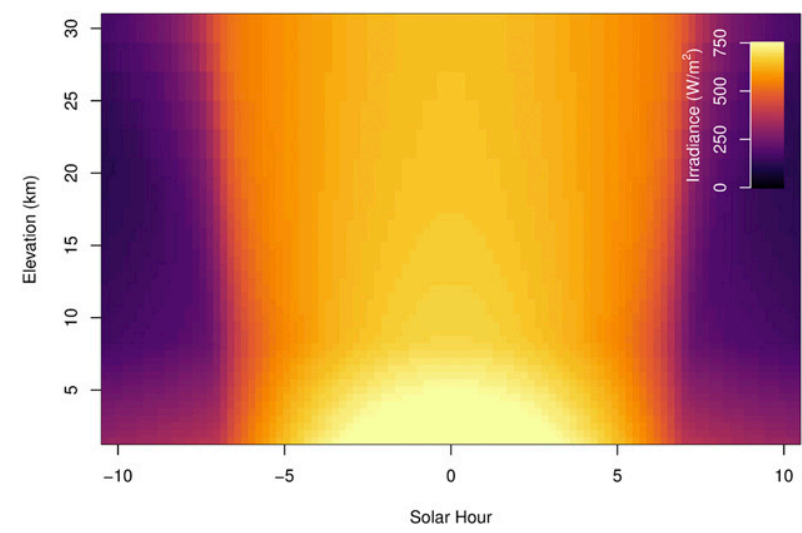

FIG. 14. Absorbed energy averaged across the balloon envelope for conditions listed in Table 2.

$$
\begin{aligned}
\dot{Q}_{\mathrm{rad}}= & \bar{\alpha}_{\mathrm{eff}}\left[I_{S} A_{\text {proj }}+I_{S, \text { sky }} A_{\text {surf }}\left(1-V_{f}\right)+I_{S, \text { ref }} A_{\text {surf }} V_{f}\right. \\
& \left.+I_{\mathrm{IR}, \text { sky }} A_{\text {surf }}\left(1-V_{f}\right)+I_{\mathrm{IR}, \text { Earth }} A_{\text {surf }} V_{f}\right] \\
& -\varepsilon_{\text {env }} \sigma_{\mathrm{SB}} T_{\mathrm{env}}^{4} .
\end{aligned}
$$

Figure 14 shows the variation in received radiation experienced by the balloon described in Table 2 at different elevations.

\section{c. Heat loss from fluid flow}

Expressions of heat transfer due to fluid flow are a function of the Reynolds number ( $\mathrm{Re})$ during ascent (because the flow is forced) and the Rayleigh number (Ra) during float, when the fluid is essentially static with respect to the envelope. The Reynolds number is defined as

$$
\operatorname{Re}=\frac{u D}{\nu},
$$

where $u$ is balloon ascent rate, $D$ is balloon diameter, and $\nu$ is kinematic viscosity $(\mu / \rho$, where $\mu$ is air viscosity and $\rho$ is air density). The Rayleigh number is defined as

$$
\mathrm{Ra}=\frac{g \beta D^{3}}{\nu \alpha}\left(T_{s}-T_{\infty}\right),
$$

where $g$ is gravitational acceleration, $\beta$ is the thermal expansion coefficient, $\alpha$ is thermal diffusivity, $T_{s}$ is the surface temperature, and $T_{\infty}$ is the ambient environmental temperature. Heat transfer for forced convection (ascending balloon) and natural convection (floating balloon) take the form

$$
\begin{aligned}
& \mathrm{Nu}_{f}=f(\mathrm{Re}, \mathrm{Pr}, \text { geometry }), \\
& \mathrm{Nu}_{n}=f(\mathrm{Ra}, \text { Pr, geometry }),
\end{aligned}
$$


where $\operatorname{Pr}$ is the Prandtl number $(\nu / \alpha \cong 0.7$ for air) and $\mathrm{Nu}$ is the Nusselt number-the ratio of convective to conductive heat transfer:

$$
\mathrm{Nu}=\frac{\bar{h} D}{k},
$$

where $k$ is the thermal conductivity and $\bar{h}$ is a surfaceaveraged heat transfer coefficient. $\mathrm{Nu}$ generally increases with $\mathrm{Re}$ and $\mathrm{Ra}$ (Holman 2009), which are themselves proportional to fluid density. Fluid density decreases exponentially with altitude, resulting in decreasing $\mathrm{Re}$ and $\mathrm{Ra}$. The consequence of this is the decreased efficiency of heat transfer via fluid flow for balloons at higher altitudes compared to those at lower altitudes.

\section{Conclusions}

The heliotrope balloon enables a class of missions formerly out of reach of institutions that do not have specialized ballooning expertise. The number of heliotrope launches has approximately doubled every year since the first successful scientific flight in 2015, and will probably double again in 2020. This flight experience has enabled us to describe the optimal construction techniques, typical trajectories, and basic physics of the balloon. We believe it is a viable option for a variety of scientific needs, ranging from small university experiments to sustained atmospheric sounding campaigns. Our short-term future plans are to engage the commercial sector to produce these balloons in bulk, create larger envelopes with heavier payloads, and develop launch techniques that can tolerate windier conditions. Over the long term, we look forward to investigating the heliotrope as a long-duration scientific platform during the polar summer and ascertaining whether it is a viable flight system for missions to Venus or Jupiter.

Acknowledgments. This manuscript is an expanded version of a white paper titled "Solar Hot Air Balloons for Terrestrial and Planetary Atmospheres" that was written for the NASA Scientific Balloon Roadmap Program Analysis Group in July 2018. The "Principle of Operation" section is largely based on an informal report by P. E. Norman and D. C. Bowman titled "Solar Balloon Buoyancy and Flight Predictions" that was written in 2014. Maps were generated using the ggmap package (Kahle and Wickham 2013). The works of S. Krishnamoorthy, A. Komjathy, M. T. Pauken, and J. A. Cutts were supported by the Jet Propulsion Laboratory, California Institute of Technology, under a contract with the National Aeronautics and Space
Administration. Partial funding for this work was provided by the NNSA Office of Defense Nuclear Nonproliferation Research and Development as well as the Laboratory Directed Research and Development program. Sandia National Laboratories is a multimission laboratory managed and operated by National Technology and Engineering Solutions of Sandia, LLC, a wholly owned subsidiary of Honeywell International, Inc., for the U.S. Department of Energy's National Nuclear Security Administration under Contract DENA0003525. The views expressed here do not necessarily reflect the views of the U.S. Government, the U.S. Department of Energy, or Sandia National Laboratories.

\section{REFERENCES}

Anderson, W. J., and I. Taback, 1991: Oscillation of high-altitude balloons. J. Aircr., 28, 606-608, https://doi.org/10.2514/3.46071.

Besset, L., 2016: The solar hot air balloons of Dominic Michaelis. Orange, http://ballonsolaire.pagesperso-orange.fr/en-historique2.htm.

Bowman, D. C., and J. M. Lees, 2013: The Hilbert-Huang transform: A high resolution spectral method for nonlinear and nonstationary time series. Seismol. Res. Lett., 84, 1074-1080, https://doi.org/10.1785/0220130025.

$\longrightarrow$, and _ 2015: Infrasound in the middle stratosphere measured with a free flying acoustic array. Geophys. Res. Lett., 42, 10 010-10 017, https://doi.org/10.1002/2015GL066570.

_, and S. A. Albert, 2018: Acoustic event location and background noise characterization on a free flying infrasound sensor network in the stratosphere. Geophys. J. Int., 213, 15241535, https://doi.org/10.1093/gji/ggy069.

Christensen, T., B. M. Knudsen, J.-P. Pommereau, G. Letrenne, A. Hertzog, F. Vial, J. Ovarlez, and M. Piot, 2007: Evaluation of ECMWF ERA-40 temperature and wind in the lower tropical stratosphere since 1988 from past long-duration balloon measurements. Atmos. Chem. Phys., 7, 3399-3409, https:// doi.org/10.5194/acp-7-3399-2007.

Dai, Q., X. Fang, X. Li, and L. Tian, 2012: Performance simulation of high altitude scientific balloons. Adv. Space Res., 49, 10451052, https://doi.org/10.1016/j.asr.2011.12.026.

Dharmalingam, S., R. Plougonven, A. Hertzog, A. Podglajen, M. Rennie, L. Isaksen, and S. Kébir, 2019: Accuracy of balloon trajectory forecasts in the lower stratosphere. Atmosphere, $\mathbf{1 0}$, 102, https://doi.org/10.3390/atmos10020102.

Farley, R. E., 2005: BalloonAscent: 3-D simulation tool for the ascent and float of high-altitude balloons. Fifth Aviation, Technology, Integration, and Operations Conf., Arlington, VA, AIAA, 2005-7412 https://doi.org/10.2514/6.2005-7412.

Garg, K., and M. R. Emami, 2019: Balloon ascent prediction: Comparative study of analytical, fuzzy, and regression models. Adv. Space Res., 64, 252-270, https://doi.org/10.1016/ j.asr.2019.03.035.

Holman, J. P., 2009: Heat Transfer. 10th ed. McGraw-Hill, 752 pp. Jones, J. A., and M. K. Heun, 1997: Montgolfiere balloon aerobots for planetary atmospheres. Int. Balloon Technology Conf., San Francisco, CA, AIAA, A97-31330, https://doi.org/10.2514/ 6.1997-1445.

- and J. J. Wu, 1999: Solar Montgolfiere balloons for Mars. Int. Balloon Technology Conf., Norfolk, VA, AIAA, AA9933302, https://doi.org/10.2514/6.1999-3852. 
Kahle, D., and H. Wickham, 2013: ggmap: Spatial visualization with ggplot2. R Journal, No. 5 (1), 144-161, https://doi.org/ 10.32614/RJ-2013-014.

Kramer, D., 2019: Helium users are at the mercy of suppliers. Phys. Today, 72, 26-29, https://doi.org/10.1063/PT.3.4181.

Kreith, F., and J. F. Kreider, 1974: Numerical prediction of the performance of high altitude balloons. NCAR Tech. Note NCAR/TN-STR+65, 146 pp., http://doi.org/10.5065/ D64X55SR.

Malaterre, P., 1993: Long duration balloon flights in the middle stratosphere. Adv. Space Res., 13, 107-114, https://doi.org/ 10.1016/0273-1177(93)90282-G.

Nastrom, G. D., 1980: The response of superpressure balloons to gravity waves. J. Appl. Meteor., 19, 1013-1019, https://doi.org/ 10.1175/1520-0450(1980)019<1013:TROSBT>2.0.CO;2.

Pommereau, J.-P., and Coauthors, 2002: Accuracy of analyzed stratospheric temperatures in the winter Arctic vortex from infrared Montgolfier long-duration balloon flights 1 .
Measurements. J. Geophys. Res., 107, 8260, https://doi.org/ 10.1029/2001JD001379.

Quinn, E. P., and R. H. Holzworth, 1987: Quasi-Lagrangian measurements of density surface fluctuations and power spectra in the stratosphere. J. Geophys. Res., 92, 10 926-10 932, https:// doi.org/10.1029/JD092iD09p10926.

Schoeberl, M. R., E. Jensen, A. Podglajen, L. Coy, C. Lodha, S. Candido, and R. Carver, 2017: Gravity wave spectra in the lower stratosphere diagnosed from Project Loon balloon trajectories. J. Geophys. Res. Atmos., 122, 8517-8524, https://doi.org/10.1002/2017JD026471.

Vincent, R. A., and A. Hertzog, 2014: The response of superpressure balloons to gravity wave motions. Atmos. Meas. Tech., 7, 1043-1055, https://doi.org/10.5194/amt-7-1043-2014.

Young, E. F., D. C. Bowman, J. M. Lees, V. Klein, S. J. Arrowsmith, and C. Ballard, 2018: Explosion-generated infrasound recorded on ground and airborne microbarometers at regional distances. Seismol. Res. Lett., 89, 1497-1506, https://doi.org/ 10.1785/0220180038. 